Vol. 8(3), pp. 051-056, June, 2018

ISSN: 2276-7797; ICV: 5.98

Copyright @2018, the copyright of this article is retained by the author(s)

DOI Link: http://doi.org/10.15580/GJMS.2018.3.061618083

http://gjournals.org/GJMS

\title{
Reproductive Outcome Following Abdominal Myomectomy at the University of Port Harcourt Teaching Hospital: A Ten-year Review
}

\section{ELI $\mathrm{S}^{1,2}$, ABAM DS $^{2}, \mathrm{KALIO}^{\mathrm{DGB}}{ }^{3}$, PEPPLE DKO $^{3}, \mathrm{NWOSU}^{2}$, GREEN $K^{2}$ and IKIMALO $\mathbf{J}^{2}$}

${ }^{1,2}$ Mother and Baby Care Global Foundation

${ }^{2}$ Department of Obstetrics and Gynaecology University of Port Harcourt Teaching Hospital.

${ }^{3}$ Department of Obstetrics and Gynaecology Braithwaite Memorial Specialist Hospital.

Article No.: 061618083

Type: Review

DOI: 10.15580/GJMS.2018.3.061618083

Submitted: $16 / 06 / 2018$

Accepted: $22 / 06 / 2018$

Published: 27/06/2018

${ }^{*}$ Corresponding Author

Eli Sukarime

E-mail: elisukarime@

gmail.com

Keywords:

Reproductive outcome, abdominalmyomectomy, University of Port Harcourt Teaching Hospital
Fertility preservation is one of the important factors to be considered postabdominal myomectomy especially for patients presenting with infertility. Studies have revealed the incidence of achieving pregnancy following myomectomy as $57 \%$.

Aim

To evaluate the reproductive outcome following abdominal myomectomy. Method

The study was a 10-year retrospective study of all the cases of uterine fibroid admitted into the gynaecological ward of the University of Port Harcourt Teaching Hospital between $1^{\text {st }}$ January 2003 and $31^{\text {st }}$ December 2012. Information were coded and analysed using SPSS version 20.

Results

Uterine fibroid accounted for $523(12.2 \%) \%$ of the 4287 gynaecological admissions during the period under review. The modal age was 33 years \pm 2 . Nulliparous women contributed the highestincidence of $43.4 \%$.. Pregnancy rate following abdominal myomectomy for infertile women in the study population was $24.4 \%$. Twenty women achieved pregnancy within 2 years post-abdominal myomectomy. This represented $32.78 \%$ of the 61 infertile patients without any other cause of infertility. Spontaneous abortion occurred in 4 patients (20\%), 7 (35\%) achieved spontaneous vaginal delivery while $9(45 \%)$ had elective Spontaneous abortion occurred in 4 patients (20\%), 7 (35\%) achieved spontaneous vaginal delivery while 9 (45\%) had elective caesarean delivery.

Conclusion

Generally, one of the reasons why women opt for myomectomy is infertility. However, this study shows the relationship between abdominal myomectomy and pregnancy outcome to be fair. 


\section{INTRODUCTION}

Leiomyomas or uterine fibroids, are the most common tumours in women whether Caucasian or negroid. ${ }^{1}$ The causal relationship between uterine fibroids and infertility remains unclear. ${ }^{2}$ It has a variable clinical presentation and its surgical management particularly in our environment is highly influenced by the desires of our women to preserve their uteri.

A 10-year retrospective analysis of all cases of uterine fibroids admitted into the gynaecological ward of the University of Port Harcourt Teaching Hospital was carried out. This was aimed at evaluating the clinical presentation, surgical treatment, post-operative morbidity and reproductive performance of these women.

\section{MATERIALS AND METHODS}

Between $1^{\text {st }}$ January, 2003 and $31^{\text {st }}$ December 2012, there were a total of 4287 gynaecological admissions at the University of Port Harcourt Teaching Hospital and 523 of those were for uterine fibroids. A retrospective analysis of 447 of these cases whose records were available to us was carried out. Information was obtained from the case records, gynaecological ward and theatre records of the patients. The data obtained includes age, parity, marital status, major symptoms and signs. Others include type of operation, findings at operations, postoperative morbidity and outcome of pregnancy after myomectomy in those patients with associated infertility. All the patients studied were the Negroid Race.

\section{RESULTS}

There were 4287 gynaecological admissions during the period under review out of which 523 were for uterine fibroids, thus uterine fibroids accounted for $12.2 \%$ of gynaecololical admissions.

Table 1: Ages Distribution of Patients with Uterine Fibroids

\begin{tabular}{lll}
\hline AGE IN YEARS & NUMBER & PERCENTAGE \\
\hline $\mathbf{2 0}$ & 7 & 1.6 \\
$\mathbf{2 1 - 2 5}$ & 40 & 8.9 \\
$\mathbf{2 6 - 3 0}$ & 89 & 20.0 \\
$\mathbf{3 1 - 3 5}$ & 134 & 30.0 \\
$\mathbf{3 6 - 4 0}$ & 68 & 15.2 \\
$\mathbf{4 1 - 4 5}$ & 60 & 13.4 \\
$\mathbf{4 5}$ & 49 & 10.9 \\
TOTAL & 447 & 100 \\
\hline
\end{tabular}

Table 1 shows the age distribution of patients with uterine fibroids requiring surgery. The age of the patients ranged from 17 to 55 years. The peak incidence (30.0\%) occurred in the age group 31-35 years. Seven patient $(1.6 \%)$ were aged 20 years and below while 49 patients $(10.9 \%)$ were above 45 years.

Table 2: Parity Distribution

\begin{tabular}{|c|c|c|}
\hline PARITY & NUMBER & PECENTAGE \\
\hline 0 & 194 & $43.4 \%$ \\
\hline 1 & 69 & $15.4 \%$ \\
\hline 2 & 50 & $11.2 \%$ \\
\hline 3 & 44 & $9.8 \%$ \\
\hline 4 & 36 & 8.0 \\
\hline 5 AND ABOVE & 54 & $12.2 \%$ \\
\hline TOTAL & 447 & $100 \%$ \\
\hline
\end{tabular}

Table 2 shows parity distribution in 447 cases of uterine fibroids. Nulliparous women contributed the highest incidence of $43.4 \%$. $12.2 \%$ of cases were in ground multiparous women.

\section{Marital Status}

$290(65 \%)$ of the patients were married, $130(29 \%)$ were single; while $18(4 \%)$ were divorce and $9(2 \%)$ widowed. $32 \%(62)$ of the 194 Nulliparous patients were married. 
Table 3: 3A Clinical Features

\begin{tabular}{lcl}
\hline \multicolumn{1}{c}{ SYMPTOMS } & NUMBER & PERCENTAGE \\
\hline LOWER ABDOMINAL SWELLING & 229 & $51.2 \%$ \\
MENORRHAGIA & 140 & $31.3 \%$ \\
INFERTILITY TORTAL & 82 & $18.4 \%$ \\
Without Tubal Disease Etc. & $(61)$ & \\
$\quad$ Primary & 37 & $8.2 \%$ \\
$\quad$ Secondary & 45 & $10.2 \%$ \\
ANAEMIA & 79 & $17.6 \%$ \\
LOWER ABDOMINAL PAIN/ & 75 & $16.8 \%$ \\
DISCOMFORT & & \\
IRREGULAR VEGINAL BLEEDING & 56 & $12.5 \%$ \\
DYSMENORHOEA & 17 & $3.8 \%$ \\
RECURRENT ABORTIONS & 11 & $2.5 \%$ \\
\hline
\end{tabular}

Multiple percentage features 389 (87.03\%)

Single percentage features $\quad 58(12.97 \%)$

3B UTERINE SIZE

\begin{tabular}{lcc}
\hline SIZE WEEKS & NO. OF PATIENTS & PERCENTAGE(\%) \\
\hline$<\mathbf{1 2}$ & 76 & 17.00 \\
$>\mathbf{1 2}$ & 371 & 83.00 \\
\hline
\end{tabular}

\begin{tabular}{lll}
\multicolumn{1}{c}{ 3C } & LOCATION OF FIBROID \\
\hline SITES & NO.OF PATIENT & PERCENTATE\% \\
\hline INTRAMURAL & 230 & 51.45 \\
SUBMUCOUS & 105 & 23.48 \\
SUBSEROUS & 94 & 21.02 \\
CERVICAL & 18 & 4.05 \\
SINGLE SITE & & $43.92 \%$ \\
MULTIPLE SITES & & $56.08 \%$ \\
\hline
\end{tabular}

The variable pattern of presentation of uterine fibroid is well illustrated in table 3 (A.B.C). The main complaints were lower abdominal swelling (51.2\%), menorrhagia
(31.3\%) and infertility (18.4\%). These complaints occur singly in $12.97 \%$ of cases and in difference combinations in $87.03 \%$ cases.

Table 4: Surgery Performed

\begin{tabular}{lll}
\hline \multicolumn{1}{c}{ TYPE OF SURGERY } & NUMBER & PERCENTAGE \\
\hline \multicolumn{1}{c}{ MYOMECTOMY } & 273 & $61 \%$ \\
TOTAL ABDOMINAL & 125 & $28 \%$ \\
HYSTERECTOMY (TAH) & & \\
TAH + BILATERAL & SALPINGO- & \\
OPHERECTOMY & 40 & $9 \%$ \\
POLYPECTOMY & & $2 \%$ \\
TOTAL & 9 & $100 \%$ \\
\hline
\end{tabular}

TABLE 4 is a summary of the various surgical procedures that were performed for uterine fibroids in the study population. Two hundred and seventy three patients $(61 \%)$ had myomectomy, $165(37 \%)$ had 
hysterectomy while 9 patients $(2 \%)$ had polypectomy. The Total Abdominal Hysterectomy (TAH) and Bilateral salpingo- oophorectomy was done for 40 postmenopausal women who had suspicious tubes and ovaries.
Pelvic adhesions were recorded in 134 (30\%) of cases. Pre and postoperative hysterosalpingo gram were done for 82 patients (18.4\%) who had infertility, (and in 61 of these there was no cause identified).

Table 5: Post Myomectomy Morbidity and Mortality

\begin{tabular}{lll}
\hline MORBIDITY & NUMBER & PERCENTAGE \\
\hline Anaemia $(\mathbf{H B}<\mathbf{1 0 . 0 g / d I )}$ & 95 & $35 \%$ \\
Pyrexia & 60 & $22 \%$ \\
Wound infection/Heamatoma & 33 & $12.2 \%$ \\
Prolonged post-operative pain & 29 & $10.9 \%$ \\
Urinary tract infection & 11 & $4 \%$ \\
Wound Dehiscence & 6 & $2.5 \%$ \\
Mortality & 3 & $1 \%$ \\
\hline
\end{tabular}

Abdominal swelling, pain and discomfort were found to occur more frequently with increasing uterine size, while menorrhagia dose not bear any constant correlation with the uterine size. The uterine size at presentation was above twelve weekscyesis in majority (83\%) table $3 b$. Majority (230 cases or $51.45 \%$ ) of the fibroids were intramural while cervical fibroids were seen in 18 $(4.03 \%)$ cases table $3 \mathrm{c}$. The fibroids were multiple in $25056.08 \%$ ) of cases and single in 197 or $43.92 \%$ of cases. 79 patients $(17.6 \%)$ had a hemoglobin concentration of less than $10.0 \mathrm{~g} / \mathrm{dl}$ and were classified as having anaemia. Dysmenorrhea was found in $3.8 \%$ of cases.
Table 5 show the postoperative morbidity and mortality associated with myomectomy. Anemia was the commonest associated morbidity found in $25 \%$ of patients after myomectomy.

The 3 mortalities from myomectomy resulted from uncorrected intra operative anemia from hemorrhage. The mortality from hysterectomy resulted from severe genital sepsis occurring on the $21^{\text {st }}$ postoperative day. The post-operative hospital stay ranged from 7to 27 days. The average stay in hospital was 10days.

Table 6: Preganancy Out Come After Myomectomy

\begin{tabular}{|c|c|c|}
\hline OUTCOME OF PREGNANCY & NUMBER & PERCENTAGE \\
\hline Abortion & 4 & $20 \%$ \\
\hline Spontaneous vaginal delivery & 7 & $35 \%$ \\
\hline Caeserean section & 9 & $45 \%$ \\
\hline
\end{tabular}

Table 6 shows the outcome of pregnancy following myomectomy in those women who presented with infertility without tubal disease or any other cause of infertility. 20 women achieved pregnancy within 2 years of surgery. This represents $32.78 \%$ of the 61 infertile patients without any other cause of infertility But $24.4 \%$ of total (82). Spontaneous abortion occurred in 4 patients (20\%), $7(35 \%)$ achieved spontaneous vaginal delivery while $9(45 \%)$ had caesarean delivery.

\section{DISCUSSION}

The result of this review showed that uterine fibroids accounted for $12.2 \%$ of all gynaecological admission in UPTH between 2003 and 2012. While this may be seen to be high, it is within the range of $7.8 \%$ recorded in zaria $^{5}$ and $8.35 \%$ in ilesha ${ }^{6}$. The true incidence in any community is however speculative. ${ }^{1,2}$ because majority of cases are asymptomatic and may be carried by patients throughout life unnoticed ${ }^{2,6}$.

Majority of the woman (50\%) were in the third and fourth decades of life as similarly reported by other workers $5,6,7,8$. also this study supports the general observation that fibroids are common in women that are relatively infertile ${ }^{9}$ and those of low parity ${ }^{10,11}$ as over half $(58.8 \%)$ were in this category. It may however occur in women of normal fertility and parity as found in $(31.2 \%)$ of cases reviewed.

The commonest clinical presentation in this review was lower abdominal swelling. The large size of the tumor consequent upon late presentation in our environment ${ }^{3,5,6,7}$ probably contributes to this clinical feature. Majority (83\%) presented when uterine size was above 12 weeks cyesis.

The report of menorrhagia being next to lower abdominal swelling in incidence is in agreement with similar study done in ilesa ${ }^{6}$, Nigeria though other workers have reported it being the commonest 
presentation in Nigeria women ${ }^{3,5,7}$. The high incidence $(74.93 \%)$ of intramural and submucous fibroid, causing increasing endometrial surface and accompanying endometrial hyperplasia, however provides explanation for the incidence of menorrhagia (31.3\%) observed in the study.

There is a recognized association between uterine fibroids, pelvic inflammatory disease and infertility ${ }^{1,7,9}$ which is higher among the negroid race. Ogunniyi and fasubaa (1990) in llesa, Nigeria reported an association of infertility in $51 \%$ of patients with uterine fibroids in their series. In this review only $18.4 \%$ of patients presented with fertility. A high incidence of pelvic inflammatory disease said to be associated with uterine fibroids may account for the rising incidence of infertility in these patients probably due to tubal factor $^{10,11,12,13}$.

Anaemia was found in $17.6 \%$ of the patients. It is a known complication of uterine fibroids resulting from menorrhagia. In some cases polycythaemia may occur due to autonomous production of erthropoetin by the myoma cells themselves ${ }^{8,10}$. This was not observed in this review.

Dysmenorhoea was noted in $3.8 \%$ of the patients in this review. Spasmodic dysmenorhoea is possible when a submucoustumour stimulates expulsive uterine contractions. Severe but one-sided dysmenorhoea can be caused by a single but small fibroid located at the utero tubal junction from which uterine contractions emanate ${ }^{8,13}$.

The reported incidence of recurrent abortions of $2.5 \%$ in this review may probably be due to implantation occurring in relation to a submucous fibroid, it has been illustrated that in $0.5 \%$ of normal pregnancies, there is coexisting uterine fibroids ${ }^{13,15}$.

Surgery as done in this study still remain the main stay of management of significant proportion of uterine fibroids ${ }^{5,6,9,11,13}$. Hysterectomy with or without bilateral salpingo-oophorectomy is curative ${ }^{17}$. However unlike in the study done in ilesa, Nigeria where majority $(60.1 \%)$ had hysterectomy it was only offered to $37 \%$ in this study. Myomectomy was utilized for the majority $(61 \%)$ who still had reproductive and menstrual desire as advised by several workers $5,7,11,16$.

Hormones were not employed in any of the patients because of age and size of the fibroid at presentation. These hormones only causes temporary remission, useful only for small fibroids ${ }^{17,8,19}$ and in woman approaching menopause 19,20,21. In this environment cost is a discouraging factor.

The pregnancy rate following myomectomy for infertile women in this review was $32.78 \%,(24.4 \%$ of total). This is within the range of $30-40 \%$ reported by other workers. The high caesarean section rate of $45 \%$ for those who carried their pregnancy to term is not surprising because of the associated infertility and advanced maternal age ${ }^{5,7,11}$.

The clinical presentation of uterine fibroids as documented in this study is similar to that of previous authors from other parts of Nigeria $3,5,6,11,17$. In our environment the surgical treatment of choice is myomectomy which carries a greater postoperative morbidity than hysterectomy ${ }^{17}$. It is possible that with availability of modern medical and surgical technique post-operative morbidity from myomectomy in our Centre would so reduce as to improve the reproductive performance of those infertility cases ${ }^{6,11,12,22}$.

\section{ACKNOWLEDGEMENT}

$\begin{array}{llll}\text { 1. MOTHER AND BABY CARE } & \text { GLOBAL } \\ \text { FOUNDATION } & & \\ \text { 2. PRIME MEDICAL CONSULTANTS, PORT } & \text { PARCOURT RIVERS STATE, NIGERIA } & \end{array}$

\section{REFERNCE}

1. Buttram V.C and Reiter R.C (1981): Uterine Leiomyomata. Aetiology symptomatology and management.fertil.steril.36:433-445.

2. Vollenhoven, B.(1998). Introduction: the epidemiology of uterine leiomyoma. Clin.obstet.gynaecol.12(2):169-79

3. Ogunbode, $O$. environmental factors in the management of uterine fibroids. In: proceedings of an international conference organize by the society of an international conference organized by the society of gynaecology and obstetrics of Nigeria ,Ibadan. O.A. Ojo, V.E. Aimakhu, O. Akinla, L.A Emmaanuel, WO. Chukwudebelu (editors). Broderna Ekstrands Trycheri A.B.,Lund.page.434-436,1977.

4. Lumsden, M.A; Wallance, E.M.: (1998): Clinical presentation of uterine fibroids. clin. obstet. gynaecol 12(2):177-95

5. Emembolu, J.O. 1987.Management uterine fibromyomata. Presentation and management in northern Nigeria. int. J. Gynaecol.obstet.25:413-416.

6. Ogunniyi, S. O., FASUBA, O.B. (1990). Uterine fibromyoma in ilesa, Nigeria. nig.med pract.vol.19 no6.

7. Hendrickse, J.P de V. Gynaecological tumors in Ibadan Dokita, 4:25-30,1972.

8. Lacey, C.G. Disorders of uterine corpus. In: R.C. Benson (ed). Current obstetric and gynaecologic diagnosis and treatment. $4^{\text {th }}$ edition, lange medical publications, los altos.pp.245-250,1982.

9. Babakua A; Rock J.A. james H.W. (1978):pregnancy success following abdominal myomectomy for inferlity. Fertile.steril.30:644.

10. Tindall, V.R. (1997) Tumours of the corpus uteri in: Jeffcoates principles of Gynaecology. $5^{\text {th }}$ Edition pp.417-432,. Edition.pp.145-149. Butterworths Ltd. London.

11. Otolorin E. O; onwude L. J. and Ladipo O.A (1989): results of myomectomy for infertility in ibadan, Nigeria. Nig.med. J. 10(4) 173-175.

12. Osoba, A.O. Sexually transmitted diseases in tropical Africa. reproductive health in Africa. Edited 
by mati.JKG, Ladipo, O.D. Burkmn, R.T Magaride, R.N. Huber D. JHPIEGO pub.

13. Jeffcoate, N. Principles of gynaecology. $4^{\text {th }}$ Edn. Snr normal jeffcoate. Butterworths pub.

14. Dewhurst, j. (1981). Integrated obstetric and gynaecology for post graduate. Ed. Sir john Dewhurst. Blackwell scientific publications.

15. Whitfield, CR. (1995). Benign tumors of the uterus. In: whitfield, C.R. (1995). Dewhursts textbook of obstetrics and gynaecology for post graduates. $5^{\text {th }}$ edn.blackwell scientific pub.london,pages.738746.

16. Adeleye J. A. and Osinusi, B.O Post operative morbidity associated with repair operations for utero vaginal prolapsed in Ibadan. nig. med. j.1997,7(3) 292-294.

17. Ezem, B. U., Otubu, j.A., 1981. Hysterectomy in the Hausa/Fulani population in Nigeria int.. j. gynaecol.obstet.19:145

18. Coutinho, E.K. (1981). Conservative treatment of uterine leiomyoma with antioestrogen and antiprogesterone 2323.int.j. obstet \& gynae.19, (5)oct.1981.357-360.

19. Friedman. A.J., Baribieri, R. L., Benacerraf, B.P., Schiff I. (1987). Treatment of leiomyomas with intranasal or subcutaneous leupromide. A goanadotrophin - releasing hormone agonist. fertile sterile 48;560-564.

20. Thomas, G.S (1993). Gonadotrophin releasing utilization before hysterectomy.din.obstet.36(3):642649.

21. RCOG (1993). Is medical management of menorrhagia obsolete? Br.J. Ostet.Gynaecol.105:569-72.

22. Agboola, A. (1988). Tumors of the corpus uteri. In: agboola, A. (ed). Textbook of obstetrics and Gynaecology for medical students. Vol.1. $1^{\text {st }}$ Edition. University services educational pub.Ltd. Lagos.

23. Obed; J.Y; Omigbodun D. A (1999) pregnancy complications following myomectomy. Sahel Medical Journal Vol.2.2 Pages 89-92. 